\title{
Human papillomavirus (HPV) contamination of gynaecological equipment
}

\author{
Caroline Gallay, ${ }^{1}$ Elodie Miranda, ${ }^{1}$ Sonja Schaefer, ${ }^{2}$ Rosa Catarino, ${ }^{2}$ \\ Martine Jacot-Guillarmod, ${ }^{3}$ Pierre-Alain Menoud, ${ }^{4}$ Frederic Guerry, ${ }^{4}$ \\ Chahin Achtari, ${ }^{3}$ Roland Sahli, ${ }^{5}$ Pierre Vassilakos, ${ }^{6}$ Patrick Petignat ${ }^{2}$
}

- Additional material is published online. To view please visit the journal (http:// dx.doi.org/10.1136/sextrans2014-051977).

${ }^{1}$ Faculty of Medicine, University of Geneva, Geneva,

Switzerland

${ }^{2}$ Department of Gynaecology and Obstetrics, Geneva University Hospitals, Geneva, Switzerland

${ }^{3}$ Department of Gynaecology and Obstetrics, Lausanne

University Hospital, Lausanne, Switzerland

${ }^{4}$ Unilabs SA, Geneva, Switzerland

${ }^{5}$ Institute of Microbiology, department of laboratories, Lausanne University Hospital, Lausanne, Switzerland

${ }^{6}$ Geneva Foundation for Medical Education and Research, Geneva, Switzerland

Correspondence to Caroline Gallay, Faculty of Medicine, University of

Geneva, Rue Michel-Servet 1, Geneva 1206, Switzerland;

Caroline.Gallay@etu.unige.ch

CG and EM contributed equally.

Received 16 December 2014 Revised 6 May 2015 Accepted 25 May 2015
To cite: Gallay $C$, Miranda E, Schaefer $S$, et al. Sex Transm Infect Published Online First: [please include Day Month Year] doi:10.1136/sextrans-2014051977

\section{ABSTRACT}

Objective The gynaecological environment can become contaminated by human papillomavirus (HPV) from healthcare workers' hands and gloves. This study aimed to assess the presence of HPV on frequently used equipment in gynaecological practice.

Methods In this cross-sectional study, 179 samples were taken from fomites (glove box, lamp of a gynaecological chair, gel tubes for ultrasound, colposcope and speculum) in two university hospitals and in four gynaecological private practices. Samples were collected with phosphate-buffered saline-humidified polyester swabs according to a standardised pattern, and conducted twice per day for 2 days. The samples were analysed by a semiquantitative real-time PCR. Statistical analysis was performed using Pearson's $\chi^{2}$ test and multivariate regression analysis.

Results Thirty-two (18\%) HPV-positive samples were found. When centres were compared, there was a higher risk of HPV contamination in gynaecological private practices compared with hospitals (OR 2.69, 95\% Cl 1.06 to 6.86). Overall, there was no difference in the risk of contamination with respect to the time of day (OR 1.79, 95\% Cl 0.68 to 4.69). When objects were compared, the colposcope had the highest risk of contamination (OR 3.02, 95\% Cl 0.86 to 10.57).

Conclusions Gynaecological equipment and surfaces are contaminated by HPV despite routine cleaning. While there is no evidence that contaminated surfaces carry infectious viruses, our results demonstrate the need for strategies to prevent HPV contamination. These strategies, based on health providers' education, should lead to well-established cleaning protocols, adapted to gynaecological rooms, aimed at eliminating HPV material.

\section{INTRODUCTION}

Human papillomaviruses (HPVs) are small doublestranded DNA viruses with a circular genome, which is enclosed in a naked capsid. HPVs infect the stratified epithelium of the skin, of the oral cavity and of the anogenital tract by accessing keratinocytes through micro-wounds and lesions. ${ }^{1}$ The majority of infections are cleared within 2 years. However, persistence of HPV and the associated chronic infection play a major role in the development of cervical cancer. ${ }^{2}$ Therefore, HPV is estimated to be responsible for up to $99 \%$ of cervical cancers, ${ }^{3} 90 \%$ of anal cancers, ${ }^{4} 65 \%$ of vaginal cancers, ${ }^{4} 50 \%$ of vulvar cancers ${ }^{4}$ and $45 \%-90 \%$ of oropharyngeal cancers. ${ }^{5}$ HPVs are classified into high-risk HPV (HR-HPV) with malignant potential and low-risk HPV (LR-HPV) causing benign lesions. ${ }^{1}$

There is conflicting evidence for HPV transmission. While skin-to-skin and mucosa-to-mucosa contact, which is predominantly by sexual intercourse, is the most frequent route of transmission, other routes might be involved. Several studies have highlighted non-sexual HPV transmission such as vertical transmission from mother to infant, ${ }^{6}$ possibly through the amniotic fluid or the placenta or via contact with the maternal genital mucosa during delivery. ${ }^{7}$

Besides direct human transmission of HPV by sexual intercourse, infection may also result from contact with contaminated equipment at gynaecological examination rooms. HPV can persist in various environmental conditions and resist disinfection by desiccation and ethanol because of its capsid properties. ${ }^{8}$ Therefore, the possibility of horizontal transfer of HPV cannot be excluded..$^{9-11}$ HPV has been detected under fingernails of patients affected with genital warts and in their underwear. ${ }^{12}$ Furthermore, HPV is also detected on several medical instruments, such as vaginal ultrasound probes and cryoguns. ${ }^{13} 14$ These data support the notion that gynaecological facilities might confer a risk of horizontal transfer, being frequently visited by infected patients. In addition, gynaecological examinations may cause micro-trauma of the genital mucosa favouring HPV infection.

This study aimed to assess whether HPV can be identified on certain types of inanimate surfaces and objects that are commonly used in gynaecological care. The panel of fomites that we selected has not been previously studied, and these are used in an everyday gynaecological practice.

\section{METHODS}

\section{Study setting}

In this cross-sectional study, samples were collected from fomites twice a day during 2 days at all study locations in October 2013. The study took place in four consulting rooms of the Gynaecology Department of the University Hospitals of Geneva, four consulting rooms of the Gynaecology Department of the University Hospital of Lausanne and four gynaecological private practices located in Geneva. Among the four consulting rooms in hospitals, there were two outpatient consultation 
rooms, one colposcopy room and one gynaecological emergency room. Besides the colposcopy room, where patients usually have Pap smear abnormalities, the other consulting rooms were used for a wide variety of patients with different complaints. Permission to visit the gynaecological care room to collect the samples was obtained by the head chief of the obstetrics and gynaecology department. All fomites were sampled in the morning before the first consultation and in the evening after all consultations, but before final cleaning (tables 1 and 2). This study did not include any information on patients, and did not test human samples. Therefore, the local ethics committee considered that patient consent was not required.

\section{Sampling}

A total of 179 samples were taken from glove boxes $(\mathrm{N}=48)$, lamps $(\mathrm{N}=48)$, gel tubes for ultrasound $(\mathrm{N}=39)$, colposcope handles $(\mathrm{N}=20)$ and from specula $(\mathrm{N}=24)$ (figure 1). Flocked swabs (FLOQSwabs 552C; Copan, Brescia, Italy) were used. These swabs contain a plastic applicator in a sterile dry tube filled with $1 \mathrm{ml}$ of sterilised RNA-free and DNA-free phosphatebuffered saline (PBS) (Sigma, Saint-Louis, Missouri, USA). Manipulation of the samples was performed under a laminar flow hood. Quality control was performed for every manipulation using negative control samples containing PBS only. Each surface was sampled according to a standardised pattern with PBS-humidified flocked swabs. After sampling, the swabs were immediately suspended in $1 \mathrm{ml}$ of PBS and stored at $4^{\circ} \mathrm{C}$. Delay between sampling and laboratory processing was not more than a maximum of 14 days.

\section{DNA extraction}

Tubes containing swabs were vortexed for $3 \times 15 \mathrm{~s}$. A volume of $400 \mu \mathrm{l}$ of each sample was used for DNA extraction, and the rest of the sample was frozen and stored. DNA extraction was performed using the $\mathrm{m} 2000 \mathrm{sp}$ with the sample preparation system kit DNA (Abbott Molecular, Illinois, USA) according to the manufacturer's recommendations. All nucleic extracts were then stored at $-20^{\circ} \mathrm{C}$ pending real-time PCR.
DNA amplification and genotyping: detection and genotyping were performed with the Anyplex II HPV28 test (HPV28; Seegene, Seoul, South Korea), according to the manufacturer's recommendations. HPV28 uses proprietary HPV-specific DPO and TOCE technologies ${ }^{15}$ to achieve HPV genotyping with high sensitivity and specificity. A total of $28 \mathrm{HPV}$ genotypes (19 HR-HPVs $(16,18,26,31,33,35,39,45,51,52,53,56,58$, 59, 66, 68, 69, 73 and 82) and 9 LR-HPVs (6, 11, 40, 42, 43, $44,54,61$ and 70)) can be distinguished by the Seegene guidebook in only two reactions using the CFX96 real-time PCR instrument (Bio-Rad), provided together with the HPV28 kits (Seegene) by BÜHLMANN Laboratories AG, Schönenbuch, Switzerland. This assay has been shown to be sensitive and specific, with a detection limit of at least five genome equivalents per PCR for the main HR genotypes of 16 or $18 .{ }^{16} \mathrm{~A}$ test sample quality control based on the beta-globin gene was performed to detect the presence of human DNA in the samples.

\section{Statistical analysis}

Data are expressed as percentages. The Pearson $\chi^{2}$ test was used to assess the relationship between each independent variable and the risk of HPV contamination (table 1). Multivariate logistic regression analysis included all variables with $p<0.10$ in the bivariate analysis to identify the predictors of HPV contamination. The variables included material, location, room and time of day (table 2). Statistical significance was accepted for $\mathrm{p}$ values $\leq 0.05$, and $95 \%$ CIs were calculated for results. ORs were adjusted for different potential confounders, such as the material, location and time of day. Data were analysed with the statistical analysis software package Stata 2009 (Stata Statistical Software: Release 11) (Stata, College Station, Texas, USA).

\section{RESULTS}

HPV DNA was detected in 32 out of the 179 (17.9\%) fomite samples. The prevalence of HPV varied according to the location, room, material and time of day. The distribution of HPV contamination of the fomites is shown in table 1. Bivariate

Table 1 Distribution of HPV contamination of 179 fomites according to location, material and time of day

\begin{tabular}{|c|c|c|c|c|c|c|c|c|c|}
\hline \multirow[b]{2}{*}{ Variable } & \multicolumn{2}{|c|}{$\begin{array}{l}\text { High-risk HPV } \\
\text { contamination }\end{array}$} & \multirow[b]{2}{*}{$p$ Value } & \multicolumn{2}{|c|}{$\begin{array}{l}\text { Low-risk HPV } \\
\text { contamination }\end{array}$} & \multirow[b]{2}{*}{$\mathrm{p}$ Value } & \multicolumn{2}{|c|}{ Contamination* } & \multirow[b]{2}{*}{$p$ Value } \\
\hline & No $(n=159)$ & Yes $(n=20)$ & & No $(n=155)$ & Yes $(n=24)$ & & No $(n=147)$ & Yes $(n=32)$ & \\
\hline Location & & & 0.264 & & & 0.091 & & & 0.008 \\
\hline Hospital $(n=110)$ & $100(62.9)$ & $10(50.0)$ & & $99(63.9)$ & $11(45.8)$ & & $97(66.0)$ & $13(40.6)$ & \\
\hline Private practice $(n=69)$ & $59(37.1)$ & $10(50.0)$ & & $56(36.1)$ & $13(54.2)$ & & $50(34.0)$ & 19 (59.4) & \\
\hline Room & & & $<0.001$ & & & $<0.001$ & & & $<0.001$ \\
\hline Ambulatory room $(n=50)$ & $49(30.8)$ & $1(5.0)$ & & 49 (31.6) & $1(4.2)$ & & $48(32.6)$ & $2(6.2)$ & \\
\hline Colposcopy room (n=28) & $19(12.0)$ & $9(45.0)$ & & 18 (11.6) & $10(41.6)$ & & $17(11.6)$ & $11(34.4)$ & \\
\hline Emergency room $(n=32)$ & $32(20.1)$ & 0 & & $32(20.7)$ & 0 & & $32(21.8)$ & 0 & \\
\hline Private practice room $(n=69)$ & $59(37.1)$ & $10(50.0)$ & & $56(36.1)$ & $13(54.2)$ & & $50(34.0)$ & 19 (59.4) & \\
\hline Material & & & $<0.001$ & & & $<0.001$ & & & $<0.001$ \\
\hline Lamp ( $n=48)$ & $41(25.8)$ & $7(35.0)$ & & $38(24.5)$ & $10(41.7)$ & & $36(24.5)$ & 12 (37.5) & \\
\hline Glove box $(n=48)$ & $47(29.5)$ & $1(5.0)$ & & $46(29.7)$ & $2(8.3)$ & & $45(30.6)$ & $3(9.4)$ & \\
\hline Colposcope $(n=20)$ & $9(5.7)$ & $11(55.0)$ & & $10(6.4)$ & $10(41.7)$ & & $6(4.1)$ & $14(43.8)$ & \\
\hline Specula $(n=24)$ & $23(14.5)$ & $1(5.0)$ & & $24(15.5)$ & 0 & & $23(15.6)$ & $1(3.1)$ & \\
\hline Gel tubes $(n=39)$ & $39(24.5)$ & 0 & & $37(23.9)$ & $2(8.3)$ & & $37(25.2)$ & $2(6.2)$ & \\
\hline Time of day & & & 0.539 & & & 0.045 & & & 0.111 \\
\hline Morning ( $n=101)$ & 91 (57.2) & $10(50.0)$ & & $92(59.4)$ & $9(37.5)$ & & $87(59.2)$ & $14(43.8)$ & \\
\hline Evening $(n=78)$ & $68(42.8)$ & $10(50.0)$ & & $63(40.6)$ & $15(62.5)$ & & $60(40.8)$ & $18(56.2)$ & \\
\hline
\end{tabular}


Table 2 Multivariate logistic regression of factors associated with HPV contamination (high-risk HPV, low-risk HPV and in general)

\begin{tabular}{|c|c|c|c|c|c|c|}
\hline \multirow{2}{*}{ Variable } & \multicolumn{2}{|c|}{ High-risk HPV contamination } & \multicolumn{2}{|c|}{ Low-risk HPV contamination } & \multicolumn{2}{|l|}{ Contamination* } \\
\hline & ORt $(95 \% \mathrm{Cl})$ & p Value & ORt $(95 \% \mathrm{Cl})$ & p Value & ORt $(95 \% \mathrm{Cl})$ & p Value \\
\hline \multicolumn{7}{|l|}{ Location } \\
\hline Hospital $(n=110)$ & & & 1 (reference) & & 1 (reference) & \\
\hline Private practice $(n=69)$ & & & 9.82 (1.14 to 84.82$)$ & 0.038 & 2.70 (1.06 to 6.86$)$ & 0.038 \\
\hline \multicolumn{7}{|l|}{ Room } \\
\hline Ambulatory room $(n=50)$ & 1 (reference) & & 1 (reference) & & 1 (reference) & \\
\hline Colposcopy room $(n=28)$ & 9.65 (1.00 to 93.5$)$ & 0.050 & 22.31 (2.29 to 217.46$)$ & 0.008 & $8.87(1.52$ to 51.81$)$ & 0.015 \\
\hline Emergency room $(n=32)$ & 0 & & 0 & & 0 & \\
\hline Private practice room $n=69$ ) & $4.62(0.50$ to 42.69$)$ & 0.176 & $9.82(1.13$ to 84.82$)$ & 0.038 & $7.12(1.41$ to 35.88$)$ & 0.017 \\
\hline \multicolumn{7}{|l|}{ Material } \\
\hline Lamp $(\mathrm{n}=48)$ & 1 (reference) & & 1 (reference) & & 1 (reference) & \\
\hline Glove box $(n=48)$ & $0.11(0.01$ to 0.97$)$ & 0.047 & $0.12(0.02$ to 0.67$)$ & 0.015 & $0.16(0.04$ to 0.66$)$ & 0.011 \\
\hline Colposcope $(n=20)$ & $3.48(0.97$ to 12.5$)$ & 0.056 & $1.56(0.45$ to 5.39$)$ & 0.482 & $3.02(0.86$ to 10.57$)$ & 0.085 \\
\hline Specula $(n=24)$ & 0.25 (0.03 to 2.51$)$ & 0.240 & 0 & & $0.14(0.015$ to 1.36$)$ & 0.091 \\
\hline Gel tubes $(n=39)$ & 0 & & $0.24(0.04$ to 1.34$)$ & 0.105 & $0.15(0.03$ to 0.82$)$ & 0.029 \\
\hline \multicolumn{7}{|l|}{ Time of day } \\
\hline Morning $(n=101)$ & & & 1 (reference) & & & \\
\hline Evening $(n=78)$ & & & 2.27 (0.78 to 6.57$)$ & 0.132 & & \\
\hline
\end{tabular}

analysis (table 1) allowed the selection of the variables for the multivariate model (table 2).

\section{Location and room}

A total of 110 samples were collected in the hospitals; out of which, $13(11.8 \%)$ were found to be positive for HPV compared with $19(27.5 \%)$ positive samples collected in private practices. HPV contamination was 2.7 times more frequent in gynaecological private practices than in hospitals (95\% CI 1.06 to $6.86, p=0.038)$. There was a higher risk to detect HPV in a colposcopy room than in an outpatient room (OR 8.9, 95\% CI 1.52 to $51.81, \mathrm{p}=0.015$ ).

\section{Fomites}

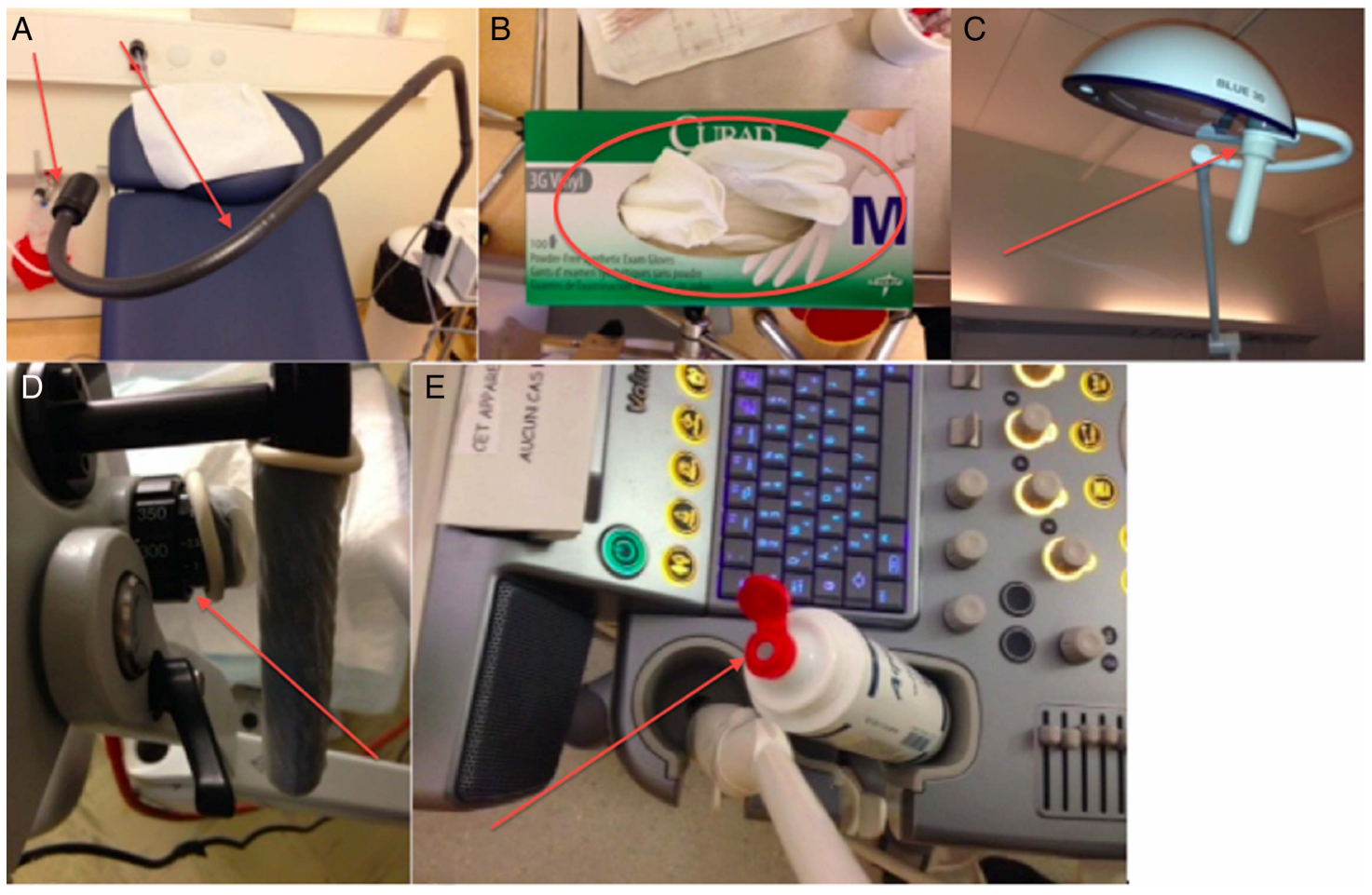

Figure 1 Samples were taken from the (A) black lamp, (B) glove box, (C) white lamp (D) colposcope handle and (E) lubricant's tube. Arrows point the exact location where samples were taken from the object. 


\section{Material}

Of the 32 positive samples, the majority was found to be associated with colposcopes (43.8\%) and lamps (37.5\%). Colposcope had a higher probability of being contaminated with HR-HPV compared with lamps (OR 3.48, 95\% CI 0.97 to 12.5, $\mathrm{p}=0.056)$.

\section{Time of day}

No difference was found in HPV contamination between morning and evening (OR 2.27, 95\% CI 0.78 to 6.57, $\mathrm{p}=0.132)$.

HPV genotype: a panel of 20 genotypes of HPV was detected in this study, consisting of 13 different HR-HPV genotypes (31, $35,39,51,52,53,56,58,59,66,68,73$ and 82). The most frequent types among HR-HPV genotypes were HPV 53 and HPV 58 (14.3\% each) followed by HPV 56, 59 and 66 (11.9\% each); HPV 31, 35 and 73 (7.1\% each); HPV 68 (4.8\%) and HPV 39, 51, 52 and 82 (2.4\% each).

For LR-HPV, seven different genotypes were found $(6,11$, 42, 43, 44, 54 and 61). HPV 42 was the most frequent LR-HPV (38.2\%), followed by HPV 6 (17.6\%). HPV 11 represented $2.9 \%$ of LR-HPV detected.

\section{Test sample quality control}

A test sample quality control based on the beta-globin gene was performed to detect the presence of human DNA in the samples, indicating that human cells can be present on surfaces. Overall, 95 of $179(53.1 \%)$ samples were positive for the amplification of beta-globin. Of the 32 samples containing HPV DNA, 29 (90.6\%) were also positive for beta-globin DNA.

\section{DISCUSSION}

In this study, $18 \%$ of 179 objects, which are part of gynaecological care, were contaminated by HPV (table 1). Our study shows that HPV contamination of fomites is a reality, despite careful cleaning. These findings are in accordance with previous studies. 9 1314

Contrary to our initial expectations, we found more contaminated fomites in gynaecological private practices than in hospitals $(59.4 \%$ vs $40.6 \%)$. The opposite result was expected because there is a higher influx of patients consulting at hospitals than at private practices. These patients are more likely to be infected with HPV, especially in the colposcopy rooms, because they are probably referred by their gynaecologist. In addition, hospital personnel were not informed of the exact date of the sampling for the study. However, for organisational reasons, the private practices were aware of the exact date of sampling. This inequality could have created a bias favouring cleaning in private practices because they could have thoroughly cleaned the environment, being aware of the exact day of the sampling. However, the difference in contamination between hospitals and private practices may be explained by the fact that hospitals might use stronger cleaning agents. Moreover, hospitals might have a stricter cleaning policy for the cleaning staff and nurses and more frequent cleaning.

The highest prevalence of HPV was found in colposcopy rooms (34.4\%), whereas the HPV prevalence found in the ambulatory rooms was of $6.2 \%$. Patients who are referred for colposcopy are more likely to be HPV carriers than patients consulting in other care rooms. Surprisingly, no HPV was detected in emergency rooms, but these rooms receive the highest number of patients. A stricter behaviour in relation to disinfection was observed in the emergency rooms. Nurses are in charge of cleaning in the rooms in between patients, which is not always the case in regular consulting rooms or gynaecological private practices.

Our finding that the colposcope handle was the most contaminated object (43.8\% of the cases) can be explained by its structure with several grooves, which are difficult to thoroughly clean. Moreover, patients who need a colposcope examination are more likely to be HPV carriers, thus increasing the probability of contamination from colposcopes. The lamp also had a high prevalence of HPV (37.5\%). During a gynaecological examination, the lamp often needs to be repositioned, especially the black lamps, which have a smaller beam than the white lamps (figure 1A,C). In addition to more frequent repositioning of black lamps, which may lead to an increased risk of contamination, black lamps have a grainy surface, which leads to cleaning obstacles, consistent with a higher probability of detection of HPV at their surface.

A few glove boxes were HPV positive during this study (9.4\%). These boxes were manipulated by many different people without any precautions.

The presence of HPV on ultrasound gel tubes $(6.2 \%$ of the cases) could have resulted from doctors touching the probe with the gel tube while performing an ultrasound examination.

Surprisingly, one speculum was found to be positive for HPV DNA. Contamination during sampling cannot be excluded, despite all of the precautions that are taken. These precautions include disinfection of hands, wearing gloves and sampling conducted with two people of whom one ensures that the swab does not touch anything, but the fomite. Another possibility is that the detected HPV DNA originates from the sterilisation procedure of the speculum (a reusable speculum) or from its packing. ${ }^{17}$ A further possible explanation might be an error during the laboratory positive analysis, leading to a false-result.

In the current study, we did not find differences between detection of HPV in the morning or evening (43.8\% vs $56.2 \%$, $\mathrm{p}=0.111$ ), but this was expected from the cumulative examination of possibly infected patients throughout the day.

HPV 53 was considered a high-risk genotype in this study according to the Seegene guidebook. HPV 53 was classified by the International Agency for Research on Cancer as a probable high-risk type, but this agency has not recommended its inclusion into HR-HPV diagnostics. 21819

We found that $53.1 \%$ of the samples were positive for betaglobin and the human DNA that was found in these samples probably came from the genital tract or other mucosa.

Our study has some limitations that need to be addressed. First, our study did not assess the presence of infectious virus on surfaces because it is only based on nucleic acid detection. Evaluation of infectious HPV is extremely difficult. The production of the virus depends on terminal differentiation of infected keratinocytes. $^{20}$ Several studies have attempted to evaluate infectivity using the organotypic (raft) culture system. ${ }^{21} 22$ Second, the exact quantity of virus that was present on objects was not assessed because the Anyplex II HPV28 is a semiquantitative assay.

Our results suggest that the following procedures could be performed. Because contaminated fomites are usually due to errors of manipulations, one way of avoiding this would be to make a protocol for healthcare workers. From the moment that the gynaecologist starts the physical examination, he/she should not further touch the environment. An example of this situation is that a nurse could be present to adjust the light during the examination or to provide a new set of gloves if needed. Another suggestion is to replace the black lamps (figure $1 \mathrm{~A}$ ) by 
other lamps that are easier to clean. Furthermore, disposable speculums could be preferred over reusable speculums to prevent contamination. Replacement of the big bottles of gel tubes with single-dose bottles could also be a solution to avoid HPV DNA on ultrasound probes.

Finally, our study highlights the issue concerning the efficiency of disinfection agents. A recent study showed that HPV 16 is resistant to several disinfectant agents that are sometimes used as sterilising agents (eg, glutaraldehyde and ortho-phthalaldehyde) in medical facilities. ${ }^{8}$ Nevertheless, hypochlorite and high concentrations of peracetic acid-silver-based disinfectant were found to be efficient against HPV $16 .^{8}$ This previous study suggests that genotypes other than HPV 16 could be resistant to several disinfectants that are used in healthcare facilities and that a better disinfectant needs to be identified.

\section{Key messages}

- There is a significant presence of HPV DNA on gynaecological fomites (mostly on lamps and colposcopes).

- There is no evidence that the HPV DNA that is found on fomites is infectious because the virus cannot be cultivated.

- Prevention of contamination is essential because of the potential carcinogenic impact of the virus, and improvement in gynaecologists' habits and efficient cleaning substances are required.

\section{Handling editor Jackie A Cassell}

Contributors CG and EM were involved in the design of the study, contributed to acquisition of clinical samples and drafted the manuscript. SS was involved in the design of the study and drafted the manuscript. RC conducted statistical analyses and drafted the manuscript. MJ-G and CA contributed to the manuscript. P-AM and FG were involved in interpretation of the laboratory samples and contributed to the manuscript. RS drafted the manuscript. PV codesigned the study and contributed to the manuscript. PP codesigned the study, supervised the research project and proofread the final document. All authors read and approved the final manuscript.

Competing interests None declared.

Provenance and peer review Not commissioned; externally peer reviewed.

\section{REFERENCES}

1 Doorbar J, Quint W, Banks $L$, et al. The biology and life-cycle of human papillomaviruses. Vaccine 2012;30(Suppl 5):F55-70.

2 Cogliano V, Baan R, Straif $K$, et al. Carcinogenicity of human papillomaviruses. Lancet Oncol 2005:6:204.
3 Walboomers JM, Jacobs MV, Manos MM, et al. Human papillomavirus is a necessary cause of invasive cervical cancer worldwide. J Pathol 1999;189:12-19.

4 De Vuyst H, Clifford GM, Nascimento MC, et al. Prevalence and type distribution of human papillomavirus in carcinoma and intraepithelial neoplasia of the vulva, vagina and anus: a meta-analysis. Int J Cancer 2009;124:1626-36.

5 Kreimer AR, Clifford GM, Boyle P, et al. Human papillomavirus types in head and neck squamous cell carcinomas worldwide: a systematic review. Cancer Epidemiol Biomarkers Prev 2005;14:467-75.

6 Smith EM, Parker MA, Rubenstein LM, et al. Evidence for vertical transmission of HPV from mothers to infants. Infect Dis Obstet Gynecol 2010;2010:326369.

7 Gavillon N, Vervaet H, Derniaux E, et al. [How did I contract human Papillomavirus (HPV)?]. Gynecol Obstet Fertil 2010;38:199-204.

8 Meyers J, Ryndock E, Conway MJ, et al. Susceptibility of high-risk human papillomavirus type 16 to clinical disinfectants. J Antimicrob Chemother 2014;69:1546-50.

9 Ding DC, Chang YC, Liu HW, et al. Long-term persistence of human papillomavirus in environments. Gynecol Oncol 2011;121:148-51.

10 Roden RB, Lowy DR, Schiller JT. Papillomavirus is resistant to desiccation. J Infect Dis 1997;176:1076-9.

11 Ferenczy A, Bergeron C, Richart RM. Human papillomavirus DNA in fomites on objects used for the management of patients with genital human papillomavirus infections. Obstet Gynecol 1989;74:950-4.

12 Sonnex C, Strauss S, Gray JJ. Detection of human papillomavirus DNA on the fingers of patients with genital warts. Sex Transm Infect 1999;75: 317-19.

13 Casalegno JS, Le Bail Carval K, Eibach D, et al. High risk HPV contamination of endocavity vaginal ultrasound probes: an underestimated route of nosocomial infection? PLOS ONE 2012;7:e48137.

14 Strauss S, Sastry P, Sonnex C, et al. Contamination of environmental surfaces by genital human papillomaviruses. Sex Transm Infect 2002;78:135-8.

15 Chun JY, Kim KJ, Hwang IT, et al. Dual priming oligonucleotide system for the multiplex detection of respiratory viruses and SNP genotyping of CYP2C19 gene. Nucleic Acids Res 2007;35:e40.

16 Estrade C, Sahli R. Comparison of Seegene Anyplex II HPV28 with the PGMY-CHUV assay for human papillomavirus genotyping. J Clin Microbiol 2014;52:607-12.

17 Estes JM, Kirby TO, Huh WK. Autoclave sterilization of instruments used on women with cervical neoplasia is an effective method of eradicating residual human papillomavirus DNA: a polymerase chain reaction-based evaluation. J Low Genit Tract Dis 2007;11:12-7.

18 Medeiros F, Yuan L, Breslin G, et al. Type-specific HPV testing as a predictor of high-grade squamous intraepithelial lesion outcome after cytologic abnormalities. J Low Genit Tract Dis 2005;9:154-9.

19 Munoz N, Bosch FX, de Sanjose S, et al. Epidemiologic classification of human papillomavirus types associated with cervical cancer. $N$ Engl J Med 2003;348:518-27.

20 Flores ER, Allen-Hoffmann BL, Lee D, et al. Establishment of the human papillomavirus type 16 (HPV-16) life cycle in an immortalized human foreskin keratinocyte cell line. Virology 1999;262:344-54.

21 Anacker D, Moody C. Generation of organotypic raft cultures from primary human keratinocytes. J Vis Exp 2012;22:e3668.

22 Buck CB, Pastrana DV, Lowy DR, et al. Generation of HPV pseudovirions using transfection and their use in neutralization assays. Methods Mol Med 2005;119:445-62. 


\section{STl Human papillomavirus (HPV) contamination of gynaecological equipment}

Caroline Gallay, Elodie Miranda, Sonja Schaefer, Rosa Catarino, Martine Jacot-Guillarmod, Pierre-Alain Menoud, Frederic Guerry, Chahin Achtari, Roland Sahli, Pierre Vassilakos and Patrick Petignat

Sex Transm Infect published online June 12, 2015

Updated information and services can be found at:

http://sti.bmj.com/content/early/2015/06/11/sextrans-2014-051977

\section{These include:}

Supplementary Supplementary material can be found at: Material http://sti.bmj.com/content/suppl/2015/06/09/sextrans-2014-051977.D

References This article cites 22 articles, 4 of which you can access for free at: http://sti.bmj.com/content/early/2015/06/11/sextrans-2014-051977 \#BIBL

\section{Email alerting \\ Receive free email alerts when new articles cite this article. Sign up in the box at the top right corner of the online article.} service

Topic
Collections

Articles on similar topics can be found in the following collections

Clinical diagnostic tests (279)

Epidemiologic studies (760)

Radiology (diagnostics) (30)

\section{Notes}

To request permissions go to:

http://group.bmj.com/group/rights-licensing/permissions

To order reprints go to:

http://journals.bmj.com/cgi/reprintform

To subscribe to BMJ go to:

http://group.bmj.com/subscribe/ 